\title{
ANALYTICAL METHOD DEVELOPMENT AND VALIDATION FOR THE SIMULTANEOUS ESTIMATION OF SOFOSBUVIR AND VELPATASVIR DRUG PRODUCT BY REVERSE PHASE HIGH PERFORMANCE LIQUID CHROMATOGRAPHY METHOD
}

\author{
KALPANA NEKKALA ${ }^{1 *}$, SHANMUKHA KUMAR J V ${ }^{1}$, RAMACHANDRAN ${ }^{2}$ \\ ${ }^{1}$ Department of Chemistry, KL University, Vaddeswaram, Guntur, Andhra Pradesh, India. ${ }^{2}$ Department of Chemistry, Acharya Nagarjuna \\ University, Nagarjuna Nagar, Guntur, Andhra Pradesh, India. Email: kalpanan227@gmail.com
}

Received: 22 September 2017, Revised and Accepted: 6 November 2017

\section{ABSTRACT}

Objectives: The purpose of the research is to develop a simple, precise, economical, accurate, reproducible, and sensitive method for the estimation of sofosbuvir and velpatasvir drug product by reverse phase high performance liquid chromatography method.

Methods: New analytical method was developed for the estimation of velpatasvir and sofosbuvir in drug product by liquid chromatography. The chromatographic separation was achieved on the C18 column (Luna $18150 * 4.6 \mathrm{~mm} 3.0 \mathrm{um}$ ) at ambient temperature. The separation achieved employing a mobile phase consists of $0.1 \% \mathrm{v} / \mathrm{v}$ formic acid in water: methanol:acetonitrile (35:40:25). The flow rate was $0.8 \mathrm{ml} / \mathrm{min}$ and ultraviolet detector at $269 \mathrm{~nm}$. The average retention time for velpatasvir and sofosbuvir found to be $2.62 \mathrm{~min}$ and $3.72 \mathrm{~min}$.

Results: The developed method was validated as per the ICH analytical method validation guidelines. All validation parameters were within the acceptable range. The assay methods were found to be linear from 80 to $240 \mu \mathrm{g} / \mathrm{ml}$ for sofosbuvir and $20-60 \mu \mathrm{g} / \mathrm{ml}$ for velpatasvir. The correlation coefficient was 0.9998 and 0.9992 for velpatasvir and sofosbuvir respectively. The mean percentage recovery for the developed method was found to be in the range of $98.4-100.4 \%$ for velpatasvir and $98.6-100.6 \%$ for sofosbuvir. The developed method was also found to be robust.

Conclusion: The developed method was found to be suitable for the routine quantitative analysis of velpatasvir and sofosbuvir in bulk and pharmaceutical dosage form. It was also concluded that developed method was accurate, precise, linear, reproducible, robust, and sensitive.

Keywords: Sofosbuvir, Velpatasvir, Isocratic, High performance liquid chromatography, C18, Formic acid, Methanol.

(c) 2018 The Authors. Published by Innovare Academic Sciences Pvt Ltd. This is an open access article under the CC BY license (http://creativecommons. org/licenses/by/4. 0/) DOI: http://dx.doi.org/10.22159/ajpcr.2018.v11i2.22465

\section{INTRODUCTION}

\section{Sofosbuvir}

The drug is used for the treatment of hepatitis C. It is only recommended for some combination of ribavirin, peginterferon-alfa, simeprevir, ledipasvir, or daclatasvir. Cure rates are 30-97\% depending on the type of hepatitis $\mathrm{C}$ virus involved. Safety during pregnancy is unclear; while, some of the medications used in combination may result in harm to the baby. It is taken by mouth.

Molecular formula: C22H29FN309P.

Molecular weight: $529.45 \mathrm{~g} / \mathrm{mol}$.

Solubility: Soluble in Methanol, Acetonitrile, and water.

Pka: 9.3.

Mechanism of action: Sofosbuvir inhibits the hepatitis C NS5B protein. Sofosbuvir appears to have a high barrier to the development of resistance.

It is metabolized to the active antiviral agent GS-461203 (2'-deoxy2 '- $\alpha$-fluoro- $\beta$-C-methyluridine-5'-triphosphate). GS-461203 serves as a defective substrate for the NS5B protein, which is the viral RNA polymerase, thus acts as an inhibitor of viral RNA synthesis. Although sofosbuvir has a 3' hydroxyl group to act as a nucleophile for an incoming NTP, a similar nucleotide analog, 2 '-deoxy-2'- $\alpha$-fluoro- $\beta$-Cmethylcytidine, is proposed to act as a chain terminator because the 2 ' methyl group of the nucleotide analog causes a steric clash with an incoming NTP.
Half-Life: Sofosbuvir has a half-life of $0.4 \mathrm{~h}$.

Route of elimination: Sofosbuvir, as a single agent, has very mild toxicity. The most common adverse reactions are a headache and fatigue.

\section{Velpatasvir}

Velpatasvir is an NS5A inhibitor which is used together with sofosbuvir in the treatment of hepatitis $\mathrm{C}$ infection of all six major genotypes.

Molecular formula: C49H54N808.

Molecular Weight: $883.02 \mathrm{~g} \cdot \mathrm{mol}-1$.

Solubility: Soluble in water, methanol, and acetonitrile.

Pka: 3.74 .

Indication: Used together with sofosbuvir in the treatment of hepatitis $\mathrm{C}$ infection of all six major genotypes.

Mechanism of action: The substance blocks NS5A, a protein necessary for hepatitis $\mathrm{C}$ virus replication and assembly.

\section{METHODS}

\section{Equipment}

The chromatographic technique performed on a waters 2695 with 2487 detector and Empower 2 software, reversed phase C18 column (Luna C18 $150 * 4.6,3 \mathrm{um}$ ) as stationary phase, ultrasonic cleaner, scaletech analytical balance, vacuum microfiltration unit with $0.45 \mu$ membrane filter was used in the study. 


\section{Materials}

Pharmaceutically pure sample of sofosbuvir and velpatasvir was obtained as gift samples from Fortune Pharma Training Institute, Sri Sai Nagar Colony, KPHB, and Hyderabad, India.

High performance liquid chromatography-grade Methanol and Acetonitrile were from qualigens reagents Pvt., Ltd. Formic acid (AR grade) was from sd fine chem.

\section{Chromatographic conditions}

The sample separation was achieved on a C18 (Luna C18 150*4.6, $3 \mathrm{um}$ ) column, aided by mobile phase mixture of $0.1 \% \mathrm{v} / \mathrm{v}$ formic acid in water: methanol:acetonitrile (35:40:25). The flow rate was $0.8 \mathrm{ml} / \mathrm{min}$ and ultraviolet detector at $269 \mathrm{~nm}$, injection volume is $10 \mu \mathrm{l}$ and ambient temperatures.

\section{Preparation of mobile phase}

Buffer preparation: Take accurately $1 \mathrm{ml}$ of Formic acid in $1000 \mathrm{ml}$ of water.

Mobile phase: Then add 35 volumes of buffer, 40 volumes of Methanol and 25 volumes of Acetonitrile mixed well and sonicated for $10 \mathrm{~min}$

Diluent: water: Acetonitrile: 50:50 v $\backslash \mathrm{v}$

\section{Preparation of standard solution}

Preparation of stock solution

A $400 \mathrm{mg}$ of pure sofosbuvir and $100 \mathrm{mg}$ velpatasvir were weighed and transferred into $100 \mathrm{ml}$ of volumetric flask and dissolved in the diluent. The flask was shaken and volume was made up to mark with diluent to give a primary stock solution containing $800 \mu \mathrm{g} / \mathrm{ml}$ of sofosbuvir and $200 \mu \mathrm{g} / \mathrm{ml}$ of velpatasvir.

\section{Calibration standards}

From the primary stock solution $1.0 \mathrm{ml}, 1.5 \mathrm{ml}, 2.0 \mathrm{ml}, 2.5 \mathrm{ml}$, and 3.0 $\mathrm{ml}$ of aliquots are pipette into $50 \mathrm{ml}$ volumetric flasks and made up to the mark with the mobile phase to give a concentrations of $80 \mu \mathrm{g} / \mathrm{ml}$, $120 \mu \mathrm{g} / \mathrm{ml}, 160 \mu \mathrm{g} / \mathrm{ml}, 200 \mu \mathrm{g} / \mathrm{ml}$, and $240 \mu \mathrm{g} / \mathrm{ml}$ of sofosbuvir and $20 \mu \mathrm{g} / \mathrm{ml}, 30 \mu \mathrm{g} / \mathrm{ml}, 40 \mu \mathrm{g} / \mathrm{ml}, 50 \mu \mathrm{g} / \mathrm{ml}$, and $60 \mu \mathrm{g} / \mathrm{ml}$ of velpatasvir.

\section{Sample solution}

Accurately weighed 20 tablets were ground to obtain fine powder equivalent to $400 \mathrm{mg}$ of sofosbuvir and $100 \mathrm{mg}$ of velpatasvir sample were weighed and transferred to $100 \mathrm{ml}$ of volumetric flask and dissolved in diluents. The flask was shaken and volume was made up to mark with diluent to give a primary stock solution. From the above solution, $2 \mathrm{ml}$ of solution is pipetted out into a $50 \mathrm{ml}$ volumetric flask and volume was made up to mark with diluent to give a solution containing $160 \mu \mathrm{g} / \mathrm{ml}$ of sofosbuvir and $40 \mu \mathrm{g} / \mathrm{ml}$ of velpatasvir.

\section{Method validation}

\section{System suitability}

The typical values for evaluating system suitability of a chromatographic procedure are relative standard deviation (RSD) $<2 \%$, tailing factor $<1.5$, and theoretical plates $>1500$. The retention time, peak area, theoretical plates, and tailing factor were evaluated for the system.

\section{Linearity}

Linearity was studied by analyzing five standard solutions covering the range of $80-240 \mu \mathrm{g} / \mathrm{ml}$ for sofosbuvir and $20-60 \mu \mathrm{g} / \mathrm{ml}$ for velpatasvir. From the primary stock solution $1.0 \mathrm{ml}, 1.5 \mathrm{ml}, 2.0 \mathrm{ml}, 2.5 \mathrm{ml}$, and 3.0 $\mathrm{ml}$ of aliquots are pipetted into $50 \mathrm{ml}$ volumetric flasks and made up to the mark with the mobile phase to give a concentrations of $80 \mu \mathrm{g} / \mathrm{ml}$, $120 \mu \mathrm{g} / \mathrm{ml}, 160 \mu \mathrm{g} / \mathrm{ml}, 200 \mu \mathrm{g} / \mathrm{ml}$, and $240 \mu \mathrm{g} / \mathrm{ml}$ of sofosbuvir and $20 \mu \mathrm{g} / \mathrm{ml}, 30 \mu \mathrm{g} / \mathrm{ml}, 40 \mu \mathrm{g} / \mathrm{ml}, 50 \mu \mathrm{g} / \mathrm{ml}$, and $60 \mu \mathrm{g} / \mathrm{ml}$ velpatasvir. A calibration curve with concentration versus peak areas was plotted by injecting the above-prepared solutions.
Limit of detection and limit of quantification

The limit of detection (LOD) and limit of quantification (LOQ) were separately determined based on standard deviation of the y-intercept and the slope of the calibration curve.

$\mathrm{LOD}=3.3 \delta / \mathrm{S}$

$\mathrm{LOQ}=10 \delta / \mathrm{S}$.

Where,

$\delta=$ The standard deviation of the response.

$\mathrm{S}=$ The slope of the calibration curve.

The slope S may be estimated from the calibration curve of the analyte.

\section{Method precision}

The precision of the method was checked by repeated preparations. The measurement of peak areas of repeated solutions (n=6) for $160 \mu \mathrm{g} / \mathrm{ml}$ of sofosbuvir and $40 \mu \mathrm{g} / \mathrm{ml}$ of velpatasvir

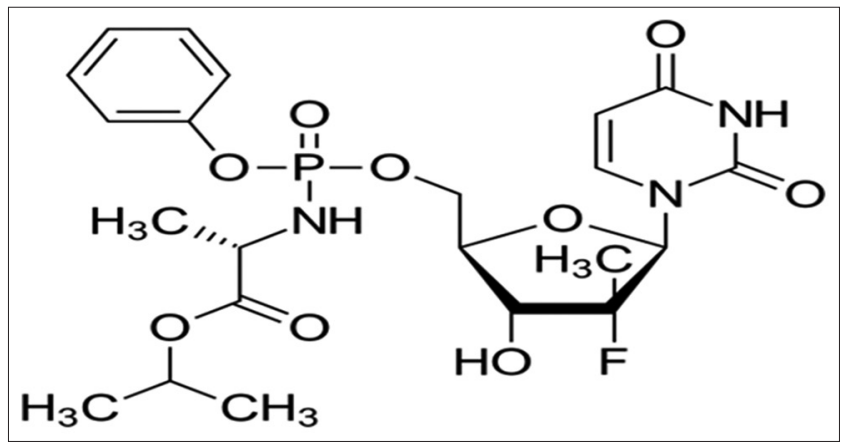

Fig. 1: Chemical structure of sofosbuvir

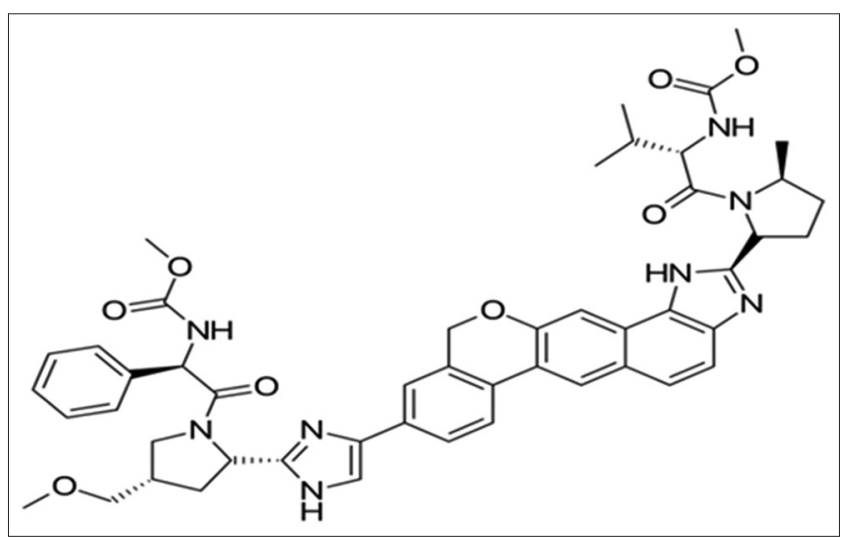

Fig. 2: Chemical structure of velpatasvir

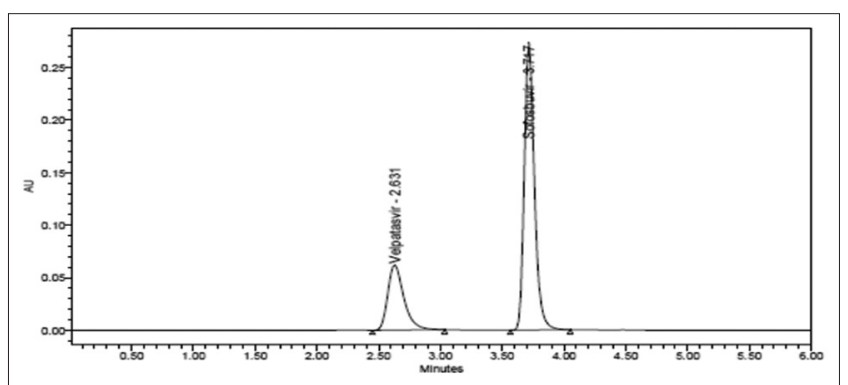

Fig. 3: Chromatogram of velpatasvir and sofosbuvir 
Accuracy

The accuracy of the method was determined by calculating the recoveries of sofosbuvir and velpatasvir by analyzing solutions containing approximately $50 \%, 100 \%$, and $150 \%$ of the working strength of sofosbuvir and velpatasvir.

\section{Robustness}

Robustness is the measure of a method remain unaffected by small, deliberate changes in method parameters such as flow rate and detection wavelength on assay of the analyte of interest. Here the detection wavelength varied $\pm 2 \mathrm{~nm}$ and flow rate was varied $\pm 0.1 \mathrm{ml} / \mathrm{min}$. The results are shown in Table 8.

\section{RESULTS AND DISCUSSIONS}

\section{System suitability}

The system suitability of the method was checked by repeated preparations for $160 \mu \mathrm{g} / \mathrm{ml}$ of sofosbuvir and $40 \mu \mathrm{g} / \mathrm{ml}$ of velpatasvir. The typical values for evaluating system suitability of a chromatographic procedure are $\mathrm{RSD}<2 \%$, tailing factor $<1.5$, and theoretical plates $>1500$. The retention time, peak area, theoretical plates, and tailing factor were evaluated for the system, system suitability data of velpatasvir and sofosbuvir are shown in Table 1.

\section{Linearity and range}

Linearity was studied by analyzing five standard solutions covering the range of $80-240 \mu \mathrm{g} / \mathrm{ml}$ for sofosbuvir and $20-60 \mu \mathrm{g} / \mathrm{ml}$ for velpatasvir. From the primary stock solution $1.0 \mathrm{ml}, 1.5 \mathrm{ml}, 2.0 \mathrm{ml}, 2.5 \mathrm{ml}$, and 3.0 $\mathrm{ml}$ of aliquots are pipetted into $50 \mathrm{ml}$ volumetric flasks and made up to the mark with the mobile phase to give a concentrations of $80 \mu \mathrm{g} / \mathrm{ml}$, $120 \mu \mathrm{g} / \mathrm{ml}, 160 \mu \mathrm{g} / \mathrm{ml}, 200 \mu \mathrm{g} / \mathrm{ml}$, and $240 \mu \mathrm{g} / \mathrm{ml}$ of sofosbuvir and $20 \mu \mathrm{g} / \mathrm{ml}, 30 \mu \mathrm{g} / \mathrm{ml}, 40 \mu \mathrm{g} / \mathrm{ml}, 50 \mu \mathrm{g} / \mathrm{ml}$, and $60 \mu \mathrm{g} / \mathrm{ml}$ velpatasvir. A calibration curve with concentration versus peak areas was plotted by injecting the above-prepared solutions. Correlation coefficient values for velpatasvir and sofosbuvir are 0.9998 and 0.9992 , respectively. The linear regression data for the calibration plot indicate a good linear relationship between peak area and concentration. The linearity data for velpatasvir and sofosbuvir are shown in Fig. 4.

\section{Precision}

The precision of the method was checked by repeated preparations. The measurement of peak areas of repeated solutions $(n=6)$ for $160 \mu \mathrm{g} /$ $\mathrm{ml}$ of sofosbuvir and $40 \mu \mathrm{g} / \mathrm{ml}$ of velpatasvir. The study was expressed as RSD of a set of results. The precision of the method (\% RSD) of was found to be $<1 \%$ showing good repeatability. The values of percentage RSD for velpatasvir and sofosbuvir are shown in Tables 2 and 3.

\section{LOD and LOQ}

The LOD and LOQ were separately determined based on standard deviation of the y-intercept and the slope of the calibration curve.

The LOD and LOQ of the proposed method were found to be 0.001 and 0.004 for velpatasvir and 0.01 and 0.03 for sofosbuvir.

\section{Accuracy study}

The accuracy of the method was determined by calculating the recoveries of sofosbuvir and velpatasvir by analyzing solutions

Table 1: System suitability data of velpatasvir and sofosbuvir

\begin{tabular}{llll}
\hline Parameter & Velpatasvir & Sofosbuvir & $\begin{array}{l}\text { Acceptance } \\
\text { criteria }\end{array}$ \\
\hline Retention time & 2.620 & 3.718 & \pm 10 \\
Theoretical plates & 2075 & 9822 & $>2000$ \\
Tailing factor & 1.34 & 1.23 & $<1.50$ \\
RSD & 0.63 & 0.42 & $<2.00$ \\
\hline
\end{tabular}

RSD: Relative standard deviation

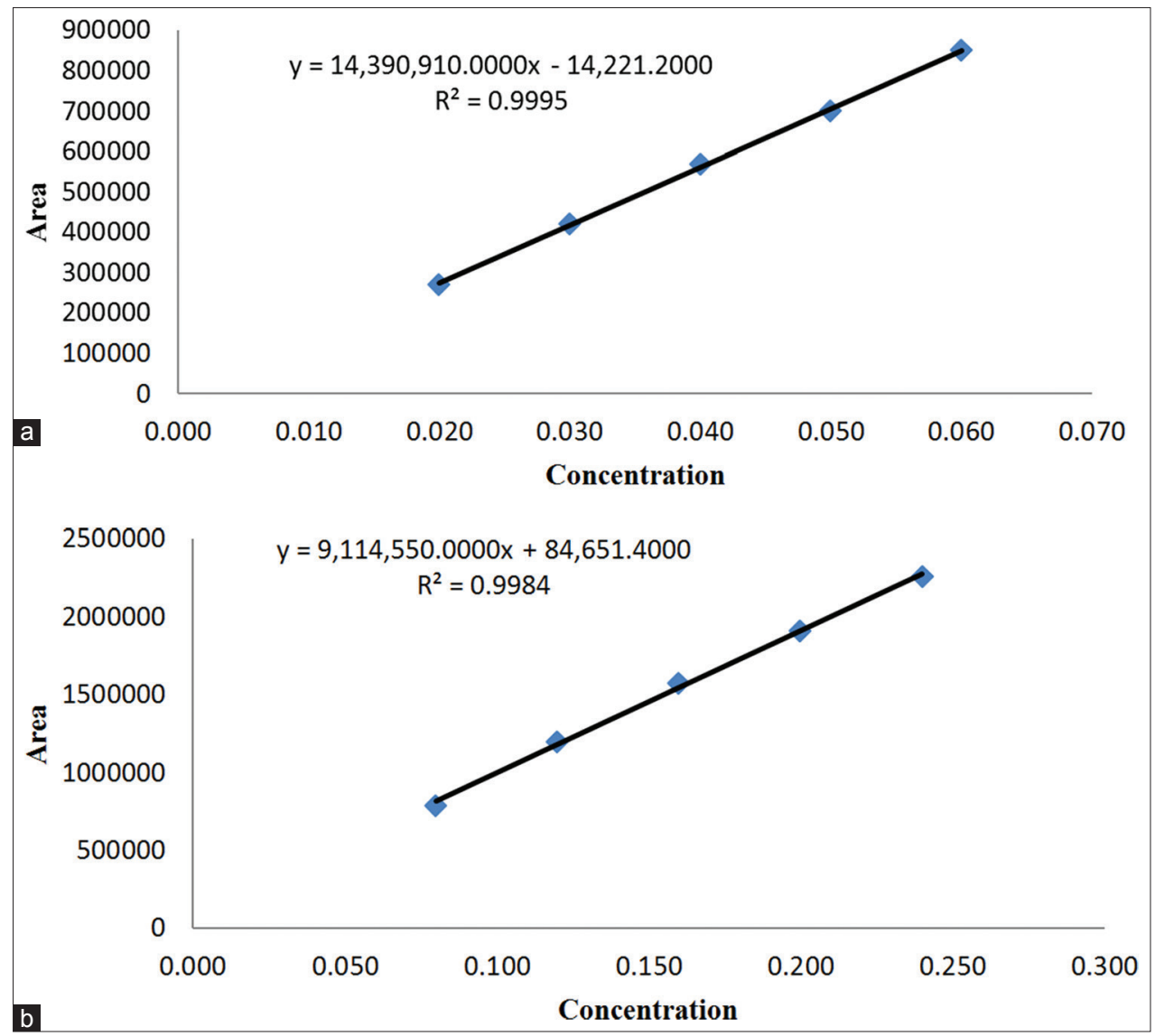

Fig. 4: Calibration curve: (a), Velpatasvir; (b), Sofosbuvir 
Table 2: Method precision data for velpatasvir

\begin{tabular}{llll}
\hline $\begin{array}{l}\text { Sample } \\
\text { number }\end{array}$ & Retention time & Peak area & Percentage assay \\
\hline 1 & 2.590 & 567139 & 100.3 \\
2 & 2.593 & 565935 & 99.5 \\
3 & 2.589 & 566080 & 99.9 \\
4 & 2.585 & 569675 & 100.0 \\
5 & 2.586 & 565706 & 99.3 \\
6 & 2.585 & 569999 & 99.8 \\
Mean \pm SD & $2.588 \pm 0.003$ & $567422 \pm 1937$ & $99.8 \pm 0.37$ \\
RSD & 0.12 & 0.34 & 0.37 \\
\hline
\end{tabular}

RSD: Relative standard deviation, SD: Standard deviation

Table 3: Method precision data for sofosbuvir

\begin{tabular}{llll}
\hline $\begin{array}{l}\text { Sample } \\
\text { number }\end{array}$ & Retention time & Peak area & Percentage assay \\
\hline 1 & 3.716 & 1576563 & 100.6 \\
2 & 3.719 & 1570565 & 99.8 \\
3 & 3.718 & 1577711 & 99.5 \\
4 & 3.715 & 1579770 & 100.2 \\
5 & 3.718 & 1573853 & 98.8 \\
6 & 3.717 & 1583134 & 100.6 \\
Mean \pm SD & $3.717 \pm 0.001$ & $1576933 \pm 4411$ & $99.9 \pm 0.69$ \\
RSD & 0.04 & 0.28 & 0.69 \\
\hline
\end{tabular}

RSD: Relative standard deviation, SD: Standard deviation

Table 4: LOD and LOQ values calculated from calibration curve

\begin{tabular}{lll}
\hline Parameter & Sofosbuvir (mg) & Velpatasvir \\
\hline LOD & 0.010 & 0.001 \\
LOQ & 0.030 & 0.004 \\
\hline
\end{tabular}

LOD: Limit of detection, LOQ: Limit of quantification

Table 5: Recovery data for velpatasvir

\begin{tabular}{lll}
\hline Accuracy level (\%) & Injection & Sample area \\
\hline 50 & 1 & 100.4 \\
& 2 & 99.7 \\
\multirow{2}{*}{100} & 3 & 98.4 \\
& 1 & 100.3 \\
\multirow{2}{*}{150} & 2 & 99.5 \\
& 3 & 99.9 \\
& 1 & 99.1 \\
& 2 & 98.6 \\
\hline
\end{tabular}

Table 6: Recovery data for sofosbuvir

\begin{tabular}{lll}
\hline Accuracy level (\%) & Injection & Sample area \\
\hline $50 \%$ & 1 & 100.1 \\
& 2 & 100.2 \\
$100 \%$ & 3 & 99.0 \\
& 1 & 100.6 \\
& 2 & 99.8 \\
$150 \%$ & 3 & 99.5 \\
& 1 & 100.0 \\
& 2 & 98.6 \\
& 3 & 99.4 \\
\hline
\end{tabular}

containing approximately $50 \%, 100 \%$, and $150 \%$ of the working strength of sofosbuvir and velpatasvir. Recovery data for velpatasvir and sofosbuvir are shown in Tables 5 and 6 .
Table 7: Robustness data for velpatasvir

\begin{tabular}{lll}
\hline Parameter & RT & Area \\
\hline Decreased flow rate $(0.7 \mathrm{ml} / \mathrm{min})$ & 2.906 & 654418 \\
Increased flow rate $(0.9 \mathrm{ml} / \mathrm{min})$ & 2.290 & 495734 \\
Wavelength $268 \mathrm{~nm}$ & 2.631 & 559851 \\
270 & 2.628 & 564858 \\
\hline
\end{tabular}

RT: Retention time

Table 8: Robustness data for sofosbuvir

\begin{tabular}{lll}
\hline Parameter & RT & Area \\
\hline Decreased flow rate $(0.8 \mathrm{ml} / \mathrm{min})$ & 4.221 & 1832255 \\
Increased flow rate $(1.2 \mathrm{ml} / \mathrm{min})$ & 3.302 & 1375616 \\
Wavelength $268 \mathrm{~nm}$ & 3.717 & 1552022 \\
270 & 3.720 & 1559976 \\
\hline
\end{tabular}

RT: Retention time

Robustness

Robustness is the measure of a method remain unaffected by small, deliberate changes in method parameters such as flow rate and detection wavelength on assay of the analyte of interest. Here the detection wavelength varied $\pm 2 \mathrm{~nm}$ and flow rate was varied $\pm 0.1 \mathrm{ml} / \mathrm{min}$. The results are shown in Table 7 and Table 8.

\section{CONCLUSION}

From the experimental results and parameters it was concluded that, this newly developed method for the simultaneous estimation of sofosbuvir and velpatasvir was found to be simple, precise, accurate and high resolution and shorter retention time makes this method more acceptable and cost-effective, and it can be effectively applied for routine analysis in research institutions, quality control department, and approved testing laboratories.

\section{CONFLICTS OF INTERESTS}

All authors declare no conflicts of interests.

\section{FINANCIAL SUPPORT AND SPONSORSHIP}

Nil.

\section{REFERENCES}

1. ICH. Q2A Validation of Analytical Procedure: Methodology International Conference on Harmonization. Geneva: ICH; 1994.

2. Chakravarthy A, Bbv S, Kumar P. Method development and validation of ultraviolet-visible spectroscopic method for the estimation of hepatitis-c drugs-daclatasvir and sofosbuvir in active pharmaceutical ingredient form. Asian J Pharm Clin Res 2016;9:61-6.

3. Zaman B, Siddique F, Hassan W. RP-HPLC method for simultaneous determination of sofosbuvir and ledipasvir in tablet dosage form and its application to in vitro dissolution studies. Chromatographia 2016;79:1605-13

4. Hassouna EM, Abdelrahman MM, Mohamed MA. Assay and dissolution methods development and validation for simultaneous determination of sofosbuvir and ledipasvir by RP-HPLC method in tablet dosage forms. J Forensic Sci Crim Invest 2017;1:505-9.

5. Devilal J, Durgaprasa B, Narottam P, Srinivasa A. New method development and validation for the determination of ledipasvir in bulk drug form by using reverse phase HPLC technique. World J Pharm Pharm Sci 2016;5:1312-21.

6. Nagaraju T, Vardhan SV, Kumar DR, Ramachandran D. A new RPHPLC method for the simultaneous assay of SOFOSBUVIR and ledipasvir in combined dosage form. Int J Chemtech Res 2017;10:761-8.

7. Rezk MR, Basalious EB, Karim IA. Development of a sensitive UPLC-ESIMS/MS method for quantification of SOFOSBUVIR and its metabolite, GS-331007, in human plasma: Application to a 
bioequivalence study. J Pharm Biomed Anal 2015;114:97-104.

8. Madhavi S, Prameelarani A. Bioanalytical method development and validation for the determination of SOFOSBUVIR from human plasma. Int J Pharm Pharm Sci 2017;9:35-41.

9. Ravichandran V, Shalini S, Sundaram KM, Rajak H. Validation of analytical methods-strategies and importance. Int J Pharm Pharm Sci 2010;2:18-22.

10. Vejendla R, Subramanyam CV, Veerabhadram G. Estimation, and validation of SOFOSBUVIR in bulk and tablet dosage form by RPHPLC. Int J Pharm 2016;6:121-7.

11. Pan C, Chen Y, Chen W, Zhou G, Jin L, Zheng Y, et al. Simultaneous determination of ledipasvir, sofosbuvir and its metabolite in rat plasma by UPLC-MS/MS and its application to a pharmacokinetic study. J Chromatogr B Analyt Technol Biomed Life Sci 2016;1008:255-9.

12. ICH. Harmonized Tripartite Guideline, Validation of Analytical Procedures: Text and Methodology in Proceedings of the International Conference on Harmonization of Technical Requirements for Registration of Pharmaceuticals for Human Use; 2005.
13. United States Food and Drug Administration. Guidance for Industry: Analytical Procedures and Methods Validation: Chemistry, Manufacturing, and Controls Documentation. Rockville, MD: Draft Guidance USFDA; 2001

14. Shi X, Zhu D, Lou J, Zhu B, Hu AR, Gan D. Evaluation of a rapid method for the simultaneous quantification of ribavirin, sofosbuvir and its metabolite in rat plasma by UPLC-MS/MS. J Chromatogr B Analyt Technol Biomed Life Sci 2015;1002:353-7.

15. Bunchorntavakul C, Reddy KR. Review article: The efficacy and safety of daclatasvir in the treatment of chronic hepatitis $\mathrm{C}$ virus infection. Aliment Pharmacol Ther 2015;42:258-72.

16. Sundaram V, Kowdley KV. Dual daclatasvir and sofosbuvir for treatment of genotype 3 chronic hepatitis $\mathrm{C}$ virus infection. Expert Rev Gastroenterol Hepatol 2016;10:13-20.

17. Patel MM, Patel HD. Development and validation of RP-HPLC method for simultaneous estimation of terbinafine hydrochloride and mometasone furoate in combined dosage form. Int J Pharm Pharm Sci 2014;6:106-9. 